\title{
PANORAMA SOCIOECONÔMICO DA PECUÁRIA LEITEIRA NO MUNICÍPIO DE PINDAÍ/BA SEMIÁRIDO BAIANO
}

Ana Maria Alves Abreu ${ }^{1}$, Glauber dos Santos ${ }^{2}$, Bruno Vinícius Castro Guimarães ${ }^{3}$, Janielen da Silva ${ }^{4}$, Gabryella Castro Guimarães ${ }^{5}$

1 Gerente de Serviços, Banco do Brasil S/A - Bacharel em Fisioterapia, especialista em MBA do Agronegócio (anamariasgc@yahoo.com.br).

2 Prof. Dr. da I-PECEGE Universidade Estadual de São Paulo - USP

3 Prof. Doutorando do Instituto Federal do Amazonas Campus São Gabriel da Cachoeira IFAM

4 Médica Veterinária, Doutoranda da ESALQ/USP.

5 Enfermeira do Instituto Federal do Amazonas Campus São Gabriel da Cachoeira IFAM

Recebido em: 08/04/2017 - Aprovado em: 10/06/2017 - Publicado em: 20/06/2017 DOI: 10.18677/EnciBio_2017A38

No semiárido nordestino a pecuária leiteira é considerada atividade relevante contribuindo tanto para o suporte alimentar quanto para a composição da renda dos agricultores que são na sua grande maioria de base familiar. O estudo foi realizado no distrito produtor de leite, microrregião do mata-veado, pertencente ao município de Pindaí-BA. O levantamento foi de natureza descritiva, no intuito de caracterizar a atividade leiteira dos produtores de leite filiados à rede dos laticínios do distrito de Pindaí-BA. Para desenvolvimento da pesquisa foram realizados levantamentos de dados primários e secundários. O uso da tecnologia, recursos agronômicos, insumos zootécnicos e assistência técnica é ainda incipiente e restrito a poucos produtores rurais. Cerca de $96,88 \%$ dos entrevistados possuem rebanhos com produtividade média inferior a 10 litros vaca ${ }^{-1} \mathrm{dia}^{-1}$, enquanto que, apenas $3,13 \%$ dos produtores superam essa realidade. A maioria dos produtores tem acesso e fazem uso das linhas de crédito para financiamento, com investimento em benfeitorias rurais, melhoramento genético dos animais, aquisição de máquinas e equipamentos. Contudo, $28,13 \%$ dos produtores estão insatisfeitos, sobretudo, com o preço pago pelo litro do leite, $R \$ 1,10$. Por fim, evidencia-se que ações públicas e institucionais no sentido de implementar serviços de assistência técnica gratuita aos produtores rurais, promoção de cursos técnicos voltados para produção sustentável e racional de alimentos visando a estação da estiagem, aperfeiçoamento das práticas de manejo sanitário e nutricional, além das políticas de valorização do principal produto rural - leite, contribuem para melhorar a produção dos rebanhos e favorecer a permanência digna do homem no campo.

PALAVRAS-CHAVE: Alimentação, Leite, Produção, Rebanho, Sistema. 


\title{
SOCIOECONOMIC OVERVIEW OF DAIRY CATTLE FARMING IN THE MUNICIPALITY OF PINDAÍ / BA SEMIÁRIDO BAIANO
}

\begin{abstract}
In the semi-arid Northeastern region, dairy farming is considered an important activity contributing both to food and nutritional support as well as to the income of farmers, who are mostly family-based. The study was carried out in the milk producing district, a micro-region of the Mata-Veado belonging to the municipality of Pindaí-BA. The survey was conducted in order to characterize the dairy activity of milk producers affiliated to the Dairy Network of the district of Pindaí-BA. In order to collect our data, primary and secondary surveys were performed. Our results show, that the use of technology, agronomic resources, zootechnical inputs and technical assistance is still incipient and restricted to few farmers. About $96.88 \%$ of the interviewees have herds with an average productivity of less than 10 liters cow-1 day -1 , while only $3.13 \%$ of the producers surpass this reality. Most producers have access to and use of credit facilities for investing in rural improvements, animal husbandry, and acquisition of machinery and equipment. However, $28.13 \%$ of the producers are dissatisfied, above all, with the price paid per liter of milk, $R \$ 1,10$. In conclusion, it is evidenced that public and institutional actions, such as the implementation of free technical assistance services to rural producers, the promotion of educational courses aimed at sustainable and rational food production during the dry season, the improvement of sanitary and nutritional management practices, and the policies of valorization of the main rural product - milk, they contribute to improve the production of the herds and to favor the dignified stay of the man of the countryside.
\end{abstract} KEYWORDS: Food, Milk, Production, Herd, System.

\section{INTRODUÇÃO}

No semiárido nordestino a pecuária de leite é considerada atividade relevante, uma vez que contribui tanto para o suporte alimentar e nutricional quanto para a composição da renda dos agricultores que são em sua maioria de base familiar. A criação das diferentes espécies animais (bovinos, ovinos, caprinos, suínos e aves), de forma isolada ou conjunta, assegura a permanência do agricultor no meio rural. Estas criações normalmente se expandem do agreste para o sertão, sendo mais resistentes à seca do que às atividades agrícolas (BRASIL, 2014). Para MOTA et al. (2010), o leite é um fator de inserção dos agricultores familiares no mercado produtor, sendo, portanto, uma das atividades rurais mais importantes para a permanência do homem no campo.

$\mathrm{Na}$ região semiárida, a criação de ruminantes, especialmente bovinos leiteiros, tem sido a atividade mais praticada pelos produtores, levando ao surgimento das bacias leiteiras dos sertões nordestinos. A bacia leiteira do Semiárido apresenta uma produção pulverizada e alicerçada em pequenas unidades da agricultura familiar. Tradicionalmente, a produção leiteira originária da agricultura familiar encontra-se atrelada a outras atividades como a fabricação de queijos artesanais e a criação de outros tipos de animais, como suínos e aves (SÁ et al., 2012).

Esta atividade permite ao produtor obter uma renda mensal devido à estratégia de agregação de valor ao leite, produzindo queijos e doces. O soro resultante da confecção de queijos é utilizado na alimentação de suínos, permitindo 
a integração com outras culturas e diversificando assim as atividades do sistema produtivo (NASCIMENTO et al., 2014). Apesar da importância da bovinocultura leiteira para os produtores familiares do semiárido, a atividade apresenta obstáculos que contribuem para uma situação de não sustentabilidade das bacias leiteiras, conforme argumentam PACHAURI \& MEYER (2015).

A bovinocultura leiteira necessita de parâmetros para avaliação de seu desempenho, análises financeiras e avaliações sistemáticas de índices zootécnicos. O manejo sanitário eficiente corresponde a uma prática obrigatória e indispensável para se alcançar um avanço na atividade leiteira. Apesar disso, em algumas propriedades não ocorre a realização ou registro de eventos zootécnicos e econômicos. Dessa forma, a gestão eficiente da propriedade rural se torna limitada e, assim, o produtor não reúne meios para alcançar o sucesso na atividade (MILKPOINT, 2014).

Estudo realizado por ALMEIDA et al. (2016) apontam que a emergência e o progresso da bacia leiteira são de natureza complexa e de mudanças rápidas e profundas no que tange às condições de produtividade e valorização do leite, evidenciando a forte capacidade de adaptação dos pequenos produtores ao mercado e às evoluções do contexto tecnológico. Tais transformações, entretanto, não se verificam de maneira homogênea; pelo contrário, elas ocorrem com grande variabilidade, resultando em uma diversidade de situações, que, por sua vez, demandam formas de apoio diversificadas.

Diante do exposto, pretendeu-se com a descrição da pecuária de leite no município de Pindaí-BA, localizado no semiárido nordestino, compreender como os fatores históricos, cenário de produção, uso das tecnologias, aspectos culturais, ambientais, políticos e mercadológicos interferem nos sistemas produtivos e nas estratégias de criação dos produtores. Diante disso, este estudo também objetivou a caracterização socioeconômica da prática leiteira entre os produtores vinculados à rede de laticínios no município de Pindaí-BA.

\section{MATERIAL E MÉTODOS}

O estudo foi realizado no município de Pindaí-BA, situado na região sudoeste do Semiárido Baiano, Microrregião do Mata-Veado, cerca de $860 \mathrm{~km}$ da capital do estado, localizado na latitude: $14^{\circ} 29^{\prime} 33^{\prime \prime} \mathrm{S}$, longitude: $42^{\circ} 41^{\prime} 14^{\prime \prime} \mathrm{W}$, altitude: 610 $\mathrm{m}$. O levantamento foi de natureza descritiva, com o intuito de definir a atividade leiteira da região Semiárida a partir do estudo entre os produtores filiados à rede de laticínio do município de Pindaí-BA.

Para desenvolver a pesquisa foi feito um levantamento de dados primários e secundários. A obtenção dos dados primários ocorreu por meio da aplicação de questionários a uma rede de produtores leiteiros do município, possibilitando determinar a estatística descritiva quantitativa e qualitativa.

A coleta de dados secundários ocorreu a partir de revistas especializadas, trabalhos, livros, artigos e pesquisas publicados em páginas da internet. Os dados utilizados nessa pesquisa foram levantados entre os meses de agosto a outubro de 2016 e os questionários aplicados enfatizaram as seguintes variáveis:

1. Perfil do produtor e sua família;

2. Perfil da atividade leiteira e sua base de produção;

3. Desenvolvimento da atividade pelos produtores segundo o nível tecnológico (técnicas de produção, preparo do solo, espaçamento, adubação, produção de 
alimentos para utilização na pecuária, prevenção e controle de doenças, melhoramento genético, entre outras ações, para maximizar e racionalizar a produção leiteira).

Os questionários foram aplicados com base na amostragem aleatória sistematizada em uma amostra de 32 produtores. $O$ valor amostral foi obtido através das Eq. (1) e Eq. (2) apresentadas a seguir (BARBETTA, 2002):

$$
\text { Eq. (1): } n 0=1 /(E 0)^{2}
$$

Eq. (2): $n=(N \times n 0) /(N+n 0)$

Onde E0: é o erro amostral estimado em 7\%, ou seja, corresponde à margem de erro definida na pesquisa; n0: é a primeira aproximação do tamanho da amostra; $\mathrm{N}$ : é a população de produtores de leite filiados ao laticínio, ou seja, 38; e n: é o número amostral levantado. Após a coleta, realizou-se a tabulação dos dados por meio da ferramenta computacional, tipo planilha eletrônica, formato Microsoft Excel $^{\circledR}$, os quais possibilitaram a análise e discussão dos resultados.

\section{RESULTADOS E DISCUSSÃO}

\section{Faixa etária dos produtores}

Ao determinar a faixa etária dos produtores, verificou-se que $37,5 \%$ possuem idade acima de 66 anos e 28,13\% dos entrevistados têm entre 51 a 65 anos; outros $31,25 \%$ apresentam faixa etária entre 36 a 50 anos e apenas 3,13\% possuem até 35 anos. Estudo realizado por CAIXÊTA (2013) constatou uma predominância de produtores com idade entre 51 e 65 anos. Em contrapartida, no trabalho feito por ZOCCAL et al. (2003) com produtores leiteiros da zona da Mata-MG constaram uma média de idade de 46 anos. Este perfil de produtores mais jovens mostrou-se antagônico ao observado neste estudo, fato que pode ser explicado pela crescente evasão da população jovem residente na zona rural do semiárido para os centros urbanos em busca de melhores oportunidades de estudo e trabalho.

\section{Nível de escolaridade dos produtores}

No que tange ao nível de escolaridade, $87,5 \%$ dos produtores possuem apenas o ensino fundamental incompleto. Resultados similares foram encontrados por NEY \& HOFFMANN (2009) ao relatarem o perfil educacional do meio rural brasileiro, onde $75 \%$ dos agricultores sequer concluíram a primeira série do ensino fundamental e $9,38 \%$ dos produtores apresentavam o ensino médio completo. Por outro lado, NEVES et al. (2011) constataram razoável grau de instrução entre os produtores de leite do Semiárido Sergipano, uma vez que $31,8 \%$ dos produtores possuíam o ensino médio completo e apenas 3,13\% com ensino fundamental.

Os demais níveis de escolaridade, ensino médio incompleto e ensino superior, não apresentaram representatividade entre os produtores entrevistados. Esses resultados podem ser explicados pela carência de investimentos públicos em educação para a comunidade da zona rural. Para NEVES et al. (2011) a escassez de capital humano associado ao baixo nível de escolaridade compromete 0 desenvolvimento rural, tornando os empreendimentos agrícolas limitados com relação a utilização de tecnologias. Além disso, a predominância do baixo nível de instrução na região estudada reflete o extremo basal da escolaridade entre os produtores leiteiros do semiárido quando comparada com outras regiões do país - 
município Orizona-GO, onde a escolaridade preponderante é o ensino superior, conforme constatado por CAIXÊTA (2013).

O alto nível instrucional entre produtores de leite é considerado uma exceção no panorama nacional, sendo restrito a pequenos núcleos de produção. LEMES (2009) argumenta que o nível de escolaridade apresenta uma possível correlação positiva entre o acesso às informações e a utilização de técnicas, métodos e tecnologias com efeito significativo no desenvolvimento social e econômico do empreendimento rural.

\section{Da posse da propriedade}

Neste estudo, $87,5 \%$ dos produtores empreendem sua atividade em área própria e $12,5 \%$ trabalham em unidade familiar. Proporção semelhante foi verificada por CAIXÊTA (2013), em que $94 \%$ e $6 \%$ dos resultados foram oriundos de propriedade própria e familiar, respectivamente. Em contrapartida, não houveram entrevistados utilizando terras arrendadas ou em regime de comodato.

\section{Possuidores de renda extra}

Em relação a fonte alternativa de renda pelos produtores, observou-se equilíbrio entre os detentores e não detentores de renda extra, sendo que $59,38 \%$ apresentaram outras fontes de renda complementares à obtida com a produção leiteira e, 40,63\% responderam não possuir outras fontes de renda. CAIXÊTA (2013) evidenciou que apenas $16 \%$ dos produtores declararam a produção de leite como atividade principal e $84 \%$ como atividade alternativa. Segundo a pesquisadora, o nível de escolaridade alto entre os produtores rurais faz com que o conhecimento de outras áreas possibilite a prática de outras atividades rentáveis, além da produção de leite.

\section{Fontes de renda extra dos produtores}

Entre os produtores detentores de renda extra, $84,22 \%$ são aposentados pelo Instituto Nacional do Seguro Social [INSS], 10,52\% são profissionais liberais e $5,26 \%$ beneficiam-se com o Programa Bolsa Família.

\section{Tipo de mão-de-obra utilizada pelos produtores}

O cenário dos produtores de leite do distrito de Pindaí-BA mostrou que $68,75 \%$ da mão-de-obra utilizada nesta atividade é proveniente do núcleo familiar, seguida da mão-de-obra contratada fixa e temporária na mesma proporção de $15,63 \%$. Este resultado pode ser explicado pelo fato dos produtores da região estudada terem baixo nível de produção, limitado nível tecnológico e famílias formadas por muitos membros, o que pode levar à alta frequência da mão-de-obra familiar na pecuária leiteira. Realidade análoga ao presente trabalho foi constatada por ZOCCAL et al. (2003) na qual o produtor ou integrante da família era o responsável pela gestão da propriedade. Em um cenário oposto, com alto nível tecnológico e de produção, a mão-de-obra contratada fixa e temporária é imperativa e indispensável na atividade leiteira (CAIXÊTA, 2013).

\section{Média de produção em litros dia $^{-1}$ vaca $^{-1}$ dos rebanhos}

O panorama da produção de leite no território nacional é ancorado nos pequenos produtores, com baixo uso da tecnologia, limitada produtividade por vaca 
e reduzido volume de produção (FERRAZZA et al. 2015). De tal modo, o cenário pesquisado, é reflexo desta realidade, visto que $50 \%$ dos entrevistados possuem rebanhos com baixa produtividade por vaca (três litros vaca ${ }^{-1} \mathrm{dia}^{-1}$ ), sendo que a produção média rural em época de estiagem não ultrapassa patamares de 20 litros em todo rebanho. Cenário oposto evidenciado por CAIXÊTA (2013) revelou uma produção diária de leite acima de 251 litros dia $^{-1}$.

A produtividade por vaca pode ser um indicativo de desenvolvimento da pecuária leiteira. Nos três estados do Sul a produtividade média foi de 2.907 litros vaca $^{-1}$ ano $^{-1}$ ao passo que em Minas Gerais, Goiás e São Paulo a produção por animal foi adjunta a média brasileira, de 1.526 litros vaca ${ }^{-1} a^{-1}$, indicando que a atividade leiteira nesta região é, predominantemente, desenvolvida em sistemas de produção com animais e alimentação pouco especializados. Rondônia e Bahia, apesar de figurar entre os 10 estados com maior volume de leite, praticam sistemas extensivo e de duplo-propósito, com produtividade média de três litros vaca ${ }^{-1} \mathrm{dia}^{-1}$, considerando 250 dias de lactação (EURICH et al. 2016).

Neste estudo, apenas pequena parcela dos entrevistados alcançou nível de produtividade maior ou igual a 13 litros vaca ${ }^{-1} \mathrm{dia}^{-1}$, sendo esse patamar de produção associado ao alto nível tecnológico, recomendações técnicas e insumos zootécnicos empregados na atividade. Entre os produtores, 96,88\% possuem rebanhos com produtividade média inferior a 10 litros vaca $^{-1}$ dia $^{-1}$, ao passo que apenas $3,13 \%$ dos produtores superam essa realidade. Todavia, a metade do rebanho leiteiro, $50 \%$ das vacas lactantes, apresentam produtividade entre dois a quatro litros dia ${ }^{-1}$. Esses percentuais podem ser um reflexo da falta de orientação ou ausência de assistência técnica adequados para o bom resultado da atividade.

NEVES et al. (2011) observaram no sistema de produção da pecuária leiteira do semiárido pernambucano melhor desempenho associado ao maior uso de tecnologia, tendo como reflexo um cenário mais produtivo e mais rentável ao produtor rural, com produtividade média de 9,3 litros vaca $^{-1}$ dia $^{-1}$ (Figura 1).

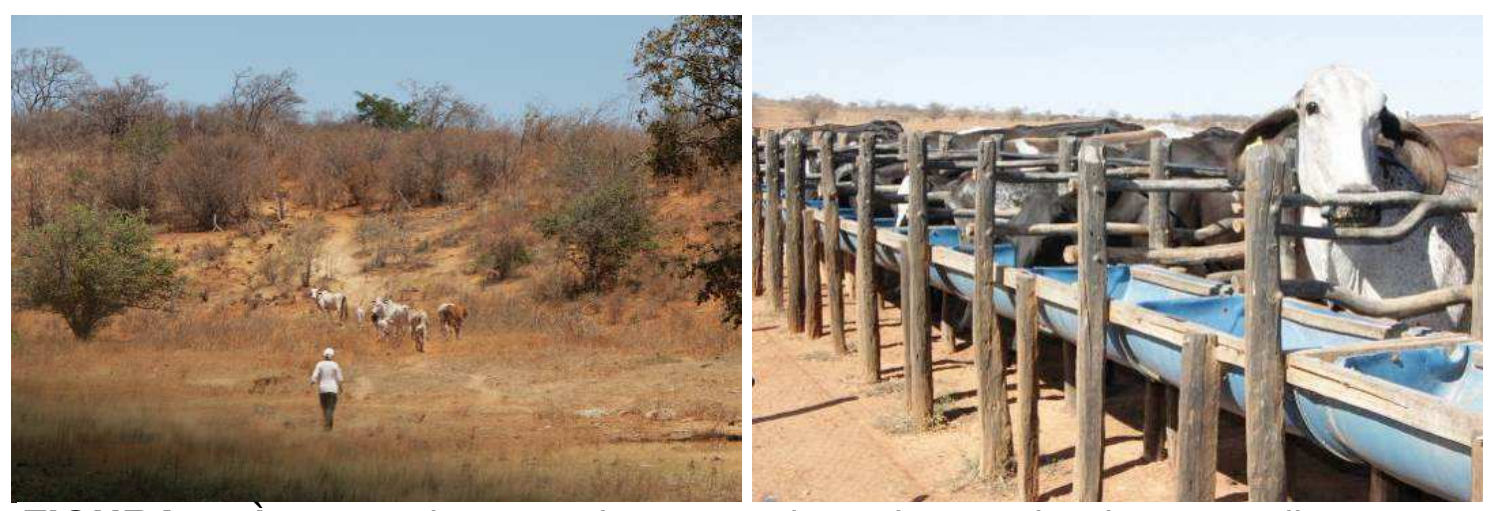

FIGURA 1- À esquerda, a produtora rural conduz o rebanho para alimentação na mata arbustiva da caatinga, à direita, evidencia-se um rebanho sendo arraçoado com alimento concentrado

Fonte: Resultados originais da pesquisa, (2016)

\section{Destino da produção}

No presente estudo, não foram constatados produtores de leite tipicamente da estação chuvosa, qualificada pela época com maior produtividade em razão da maior oferta de alimentos. Para SALGADO (2013) a necessidade de uma receita 
mensal na propriedade favorece a produção de leite em fluxo contínuo, embora o período seco seja marcado com reduções significativas no volume produzido. De modo semelhante, em todas as propriedades, a renda do leite é complementada com o comércio dos bezerros - o leite atende as despesas mensais, enquanto que a venda de bezerros cobre despesas maiores, como pequenos investimentos e aquisição de insumos.

Ao observar o destino da produção, evidenciou-se que $87,5 \%$ dos entrevistados realizam a venda para laticínios e 12,5\% destinam o leite para a produção de seus derivados como requeijão e queijo. Dentre os entrevistados não houve quem realizasse entrega do leite para cooperativas.

A lacuna de uma cadeia leiteira mais eficiente se configura como um dos principais obstáculos para a prática desta atividade. Os pequenos produtores, em especial, são os mais afetados pela ausência de articulação com cooperativas, pois a baixa valorização do preço do leite desestimula mais investimentos na produção leiteira. Por outro lado, para os laticínios, a logística na coleta do leite em núcleos distantes não favorece o aumento do valor pago pelo leite (Figura 2) (EMBRAPA, 2014).
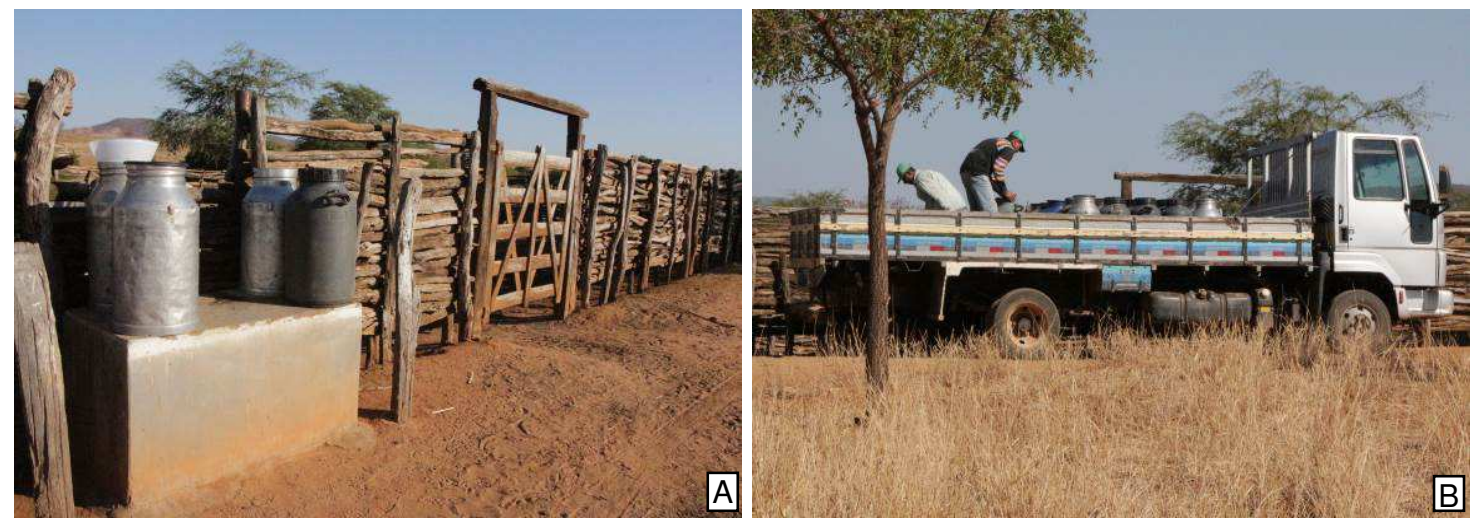

FIGURA 2- Logística de coleta do leite na região semiárida, balcão de apoio para os latões (A) e caminhão para o transporte (B)

Fonte: Resultados originais da pesquisa, (2016)

\section{Área total da propriedade}

Quanto à área da propriedade, 43,75\% dos entrevistados disseram ter uma área total entre 10 a 30 hectares, 18,75\% possuem de 31 a 45 hectares, 3,13\% possuem de 46 a 60 hectares de área e 34,38\% dos produtores possuem propriedades rurais acima de 61 hectares.

\section{Alimentação do rebanho leiteiro}

De acordo com o Instituto Nacional de Colonização e Reforma Agrária INCRA (BRASIL, 2016), os imóveis rurais são classificados em relação ao tamanho da área e a localização geográfica, sendo: Minifúndio - imóvel rural com área inferior quatro hectares; Pequena Propriedade - imóvel de área compreendida entre quatro e 16 hectares; Média Propriedade - imóvel rural de área superior a 16 e até 60 hectares; Grande Propriedade - imóvel rural de área superior 60 hectares.

Com base nos dados descritos acima, pode-se concluir que $34,38 \%$ das propriedades rurais são classificadas pelo INCRA como Grande Propriedade, não sendo constatado Minifúndio rural com área inferior a quatro hectares. Portanto ao ENCICLOPÉDIA BIOSFERA, Centro Científico Conhecer - Goiânia, v.14 n.25; p.408 2017 
considerar o patrimônio em terra percebe-se que a produtividade média rural é extremamente baixa. Uma possível solução ou alternativa para maximizar os índices produtivos, sobretudo em propriedades com áreas ociosas, seria reduzir o tamanho da área e direcionar recursos para aumento da produção de leite vaca ${ }^{-1}$. Para SOARES (2012), o investimento em insumos zootécnicos, tecnologia, melhoramento genético, instalações, entre outros componentes da produção leiteira, proporciona reflexos positivos ao empreendimento rural.

Em relação à alimentação animal, $100 \%$ dos produtores de leite utilizam as pastagens como principal fonte de forragem, outros $18,75 \%$ afirmaram utilizar a silagem para complementar a pastagem e 90,63\% utilizam além da pastagem e da silagem, alimentos concentrados para complementar a alimentação do rebanho. Além disso, uma pequena parcela dos produtores $(6,25 \%)$ adiciona na alimentação animal biomassa de capim napier (Pennisetum purpureum Schumach). Por fim, a palma forrageira (Opuntia ficus-indica, Mill.) é utilizada por $62,50 \%$ dos produtores para a alimentação do rebanho, a qual é considerada uma fonte energética e proteica de grande potencial na nutrição e manutenção de ruminantes no Nordeste brasileiro (AGUIAR et al., 2015a).

$\mathrm{Na}$ Bahia, a cultura tem sido utilizada predominantemente nas áreas de sequeiro nos municípios situados no semiárido. Estudos contemporâneos apontam a palma como recurso alimentar estratégico e de alto desempenho na dieta de novilhas leiteiras no Sudoeste baiano (AGUIAR et al., 2015b). No entanto, a inserção da cultura nos sistemas de produção de leite da região estudada esbarra no patamar de $62,50 \%$ das propriedades rurais, resultado pouco expressivo quando comparado com as pastagens e fornecimento de concentrados.

Ao considerar que a alimentação animal corresponde a aproximadamente $60 \%$ dos custos totais de produção de leite, uma opção viável para diminuir essa dependência é o uso de alternativas forrageiras adaptadas, além de observar as recomendações dos sistemas de alimentação que levem em consideração os requisitos nutricionais (proteína, energia, minerais e vitaminas) para cada categoria animal do rebanho e a composição química dos alimentos utilizados, conforme argumentaram NEVES et al. (2011).

No campo oposto da produção leiteira, CAIXÊTA (2013), relatou a baixa utilização das pastagens como fonte alimentar, ao passo que em outras regiões do Sudeste, a utilização de concentrados e forrageiras prevalecem na alimentação dos ruminantes.

ALMEIDA et al. (2016) acrescentam que o produtor rural não deve ser focado apenas em otimizar os rendimentos, mas principalmente em reduzir os riscos das perdas decorrentes da estação seca. Assim, o empreendimento rural deve contemplar a gestão do risco em que, por exemplo, o cultivo da palma estabelece estratégias para minimizar os prejuízos econômicos e materiais. Isso se justifica e se faz necessário no cenário produtivo do semiárido que é altamente vulnerável às condições climáticas.

Não obstante, a prática da ensilagem na região atesta a capacidade do pequeno produtor para incorporação de novas tecnologias, uma vez que permite aos produtores a obtenção de maiores produtividades de leite durante períodos de escassez de alimento. Por outro lado, a produção de leite por meio do uso de concentrados e insumos externos se faz necessária na inexistência ou insuficiência de alimentos no meio rural, o que eleva o custo de produção, sendo uma perspectiva 
desfavorável na relação preço dos insumos/preço do produto (SILVA \& SILVA, 2016).

\section{Principais raças que compõe o rebanho leiteiro}

A predominância do rebanho leiteiro para a região em estudo tem destaque para o gado mestiço, fato também observado por WIRBISKI et al. (2009) com a atividade leiteira no estado do Paraná. As Raças Girolanda em diversos índices de cruzamento entre Raças Gir e Holandês (1/2, 3/4, 5/8) e, em pequena proporção, a Raça Jersey, sucedem o rebanho mestiço nesta ordem. Ainda, $15,63 \%$ dos produtores utilizam simultaneamente rebanho diversificado com as Raças Girolanda e Nelore. Outros, 6,25\% têm rebanho composto com as Raças Jersey e Nelore, apesar dessa última raça não ser adequada à produção. $O$ gado mestiço, também caracterizado como Sem Raça Definida (SRD), é o mais utilizado na região semiárida por ser mais resistente e adaptado às condições adversas. Por outro lado, essas características também estão associadas aos baixos níveis de produtividade de leite vaca ${ }^{-1}$ dia $^{-1}$. CAIXÊTA (2013) verificou excelentes indicadores produtivos com às Raças Girolanda, Holandesa e Jersey na região Centro-Oeste do Brasil.

\section{Índice de satisfação com relação a atividade leiteira}

No que diz respeito ao nível de satisfação em relação a atividade leiteira, $71,88 \%$ dos entrevistados estão otimistas com os resultados e buscam destinar mais investimentos ao setor leiteiro, todavia, $28,13 \%$ estão insatisfeitos, sobretudo com o valor pago pelo leite tanto na estação seca quanto no período chuvoso, fato que pode favorecer o abandono da atividade econômica.

No tocante ao nível de satisfação do empreendimento rural, NEVES et al. (2011) reportam que os produtores de leite do Perímetro Irrigado Senador Nilo Coelho mantêm-se motivados quanto ao futuro da pecuária leiteira. Apesar disso, FERRAZZA et al. (2015) acrescentam que existem diversas limitações para o desenvolvimento da cadeia produtiva do setor leiteiro na região Nordeste, entre as quais, a baixa efetividade dos serviços de extensão rural, o que torna necessária a implantação de um programa efetivo de assistência ao produtor com a participação de grupos de técnicos regionais especializados na atividade.

Neste contexto, SILVA \& SILVA (2016), ao avaliarem os efeitos da implantação de técnicas agropecuárias sobre a intensificação da produção de leite em estabelecimentos rurais, verificaram que o conjunto de práticas implantadas nos diferentes sistemas de produção proporciona melhorias significativas na produção de leite $a n o^{-1}$, na produção de leite ha $^{-1} \mathrm{ano}^{-1}$, na produção de vaca ano ${ }^{-1}$, na receita e no aumento patrimonial. Além disso, segundo os pesquisadores, deve-se buscar o desenvolvimento da atividade com a aplicação de tecnologias adaptadas à região.

\section{Manejos sanitários mais utilizados}

Quanto ao desenvolvimento da atividade e o nível de tecnologia utilizada, identificou-se que $100 \%$ dos produtores pesquisados fazem as vacinações contra Febre Aftosa e administram vacina contra os sete males, produto constituído de culturas padronizadas e inativadas de Clostridium chauvoei, C. novyi, C. septicum, C. sordellii, C. perfringens, contra carbúnculo sintomático, gangrena gasosa e enterotoxemia dos bovinos. Apenas $25 \%$ dos produtores realizam controle de ecto e endoparasitas, por não serem uma causa comum de danos econômicos na região 
semiárida. O controle de mastite, a prática do casqueamento dos animais e a realização de exames clínicos não fazem parte da rotina dos empreendedores rurais entrevistados. NEVES et al. (2011) observaram que a prática da vacinação no semiárido pernambucano é deficiente, ainda assim, $96,4 \%$ das propriedades vacinam contra aftosa. CAIXÊTA (2013) acrescenta que a saúde dos animais favorece a produção do rebanho, tornando-se, portanto, um fator crucial na viabilidade econômica da atividade leiteira.

\section{Sistema de pastagem mais utilizada pelos produtores}

O sistema mais utilizado na região produtora de leite é o pastejo contínuo, seguido do pastejo rotacionado - denominado como piquete, sendo esses sistemas desenvolvidos em $62,5 \%$ e $43,75 \%$ das propriedades rurais, respectivamente. 0 pastejo rotacionado é o mais adequado por promover maior capacidade de suporte por unidade animal, porém apresenta maior custo de implantação com cercas de contenção, quando comparado a pastagem contínua. Isso, favorece a menor utilização desse sistema. Apenas 3,13\% dos produtores recorrem a pastagem de aluguel na estiagem e 6,25\% utilizam a reserva de pasto para a estação seca pastagem diferida; outros $9,38 \%$ dos produtores confinam o rebanho e fornecem alimentação via cocho com concentrado, palma e silagem.

\section{Forragens mais utilizadas}

A forragem mais empregada é a variedade do capim buffel grass (Cenchrus ciliares L.), sendo utilizada por $100 \%$ dos produtores; $46,88 \%$ utilizam preferencialmente a grama batatais, conhecida como grama de pasto, (Paspalum Notatum Fluegge) e/ou bengo (Brachiaria mutica (Forsk.) Stapf), nas áreas baixas denominadas de vazantes; 6,25\% utilizam o gênero Urochloa, principalmente $U$. brizantha cv. Marandu. Já no estado de Mato Grosso, segundo SILVA \& SILVA (2016), têm-se a utilização de silagem associada ao fornecimento de ração e, ou, o emprego das variedades forrageiras pertencentes ao gênero Panicuns mais indicados para vacas leiteiras como o Mombaça e o Piatã, em detrimento do capim Brachiara e suas variações.

\section{Método de reprodução}

Com relação a reprodução, 90,63\% dos produtores utilizam a forma de acasalamento por monta natural e apenas 9,38\% fazem uso da inseminação artificial como principal método de reprodução, o que caracteriza a baixa inserção da tecnologia no desenvolvimento da atividade. Condição compatível foi observada por NEVES et al. (2011) com a utilização da monta natural em 96,4\% dos rebanhos leiteiros. Situação inversa foi constatada por CAIXÊTA (2013) na região do Orizona$\mathrm{GO}$, na qual a pesquisadora evidenciou que $81 \%$ da reprodução ocorre por meio da inseminação artificial.

\section{Benfeitorias utilizadas no manejo da produção}

Todos os entrevistados responderam utilizar estábulo e curral para conduzir o manejo da ordenha, embora a estrutura física das instalações sejam bastante heterogêneas. Todavia, $6,25 \%$ dispõem de sala especializada para ordenha mecânica. Nenhum dos produtores utiliza freezer ou geladeira para estocar a matéria prima. 


\section{Máquinas e equipamentos utilizados no sistema produtivo}

O sistema de produção da região estudada tem como base a ordenha manual, a qual é exercida por $93,75 \%$ dos produtores rurais. As máquinas e equipamentos de ordenha fazem parte de um grupo restrito de produtores de leite, correspondendo a $6,25 \%$ (Figura 3). No entanto, a região estudada não apresenta resfriadores de leite, sendo a produção, por menor que seja destinada diariamente aos laticínios. CAIXÊTA (2013) compartilha em seus estudos sobre a produção de leite com a utilização de alto nível tecnológico, com ordenhadeira mecânica e resfriadores a granel, situação divergente ao presente trabalho.
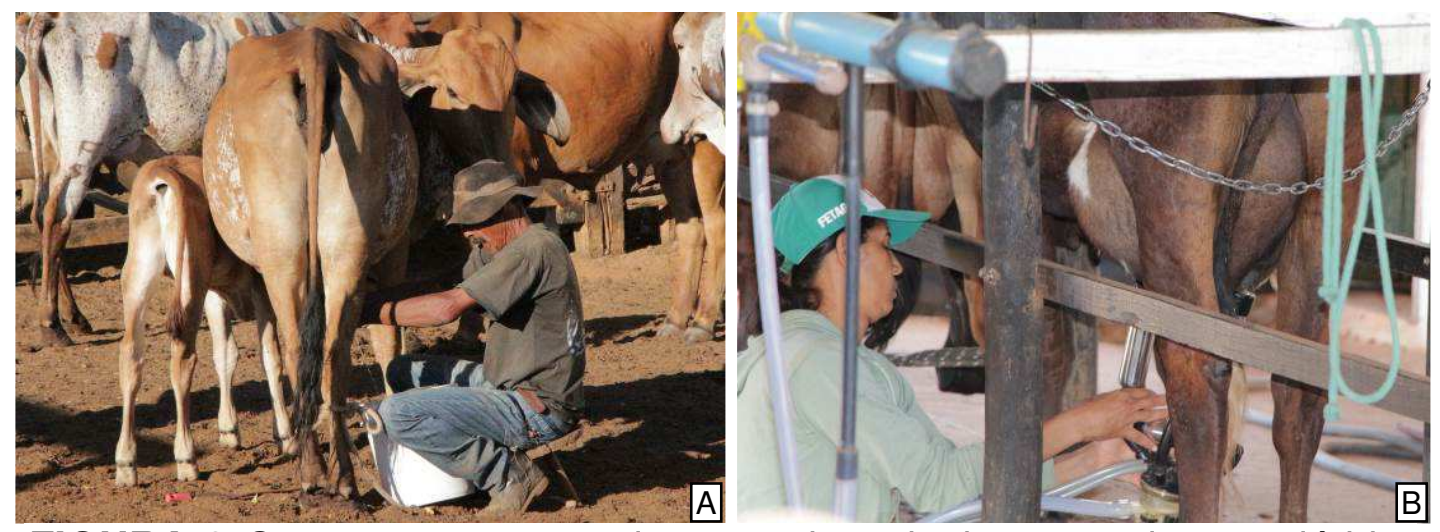

FIGURA 3 Contraste entre os sistemas de ordenha na região semiárida: manual (A) e mecânico (B)

Fonte: Resultados originais da pesquisa, (2016)

\section{Utilização de linhas de crédito para financiamento da atividade}

No tocante ao financiamento da produção, $87,50 \%$ dos entrevistados utilizam alguma modalidade de financiamento, porém, $12,50 \%$ disseram não utilizar financiamentos por algum motivo não identificado na pesquisa.

\section{Áreas de aplicação dos financiamentos}

Dos $87,5 \%$ produtores que utilizam algum tipo de financiamento, $100 \%$ deles disseram utilizar recursos de fonte oficial, sendo que cerca de $65 \%$ empregam o capital para comprar animais, $18 \%$ investem na aquisição de máquinas, $65,63 \%$ utilizam o recurso na formação de pastagem, 6,25\% utilizam para perfuração de poços artesianos, $34,38 \%$ investem em cercas, e 3,13\% utilizam para fazer custeio de despesas pecuárias.

\section{Nível de tecnologia empregado na atividade}

Entre os produtores entrevistados, $75 \%$ afirmaram que o nível de tecnologia empregado em sua propriedade é baixo; $21,88 \%$ acreditam empregar um nível médio de tecnologia e apenas $3,13 \%$ dos produtores se enquadram no nível alto de produção por meio da tecnologia. Para CAMPOS (2007), o uso da técnica ou tecnologia na atividade leiteira maximiza o sistema de produção e contribui para aumentar a oferta de leite para a população a menores custos.

Neste contexto, o uso da tecnologia associada à produção de alimentos para ruminantes, com destaque para palma forrageira, tem sido ampliado em vários estados do Nordeste e, de modo recente, o território baiano tem intensificado os ENCICLOPÉDIA BIOSFERA, Centro Científico Conhecer - Goiânia, v.14 n.25; p.412 2017 
trabalhos sobre pesquisa e produção dessa cultura no semiárido nordestino (AGUIAR et al., 2015a; AGUIAR et al., 2015b; SILVA et al., 2016; BARROS et al., 2016; PADILHA JUNIOR et al., 2016). Contudo, o sistema agrícola da região ainda é caracterizado como inconsistente e de nível tecnológico primitivo, o que favorece produtividade inferior ao potencial da cultura, conforme argumentam SILVA et al. (2016) (Figura 4).

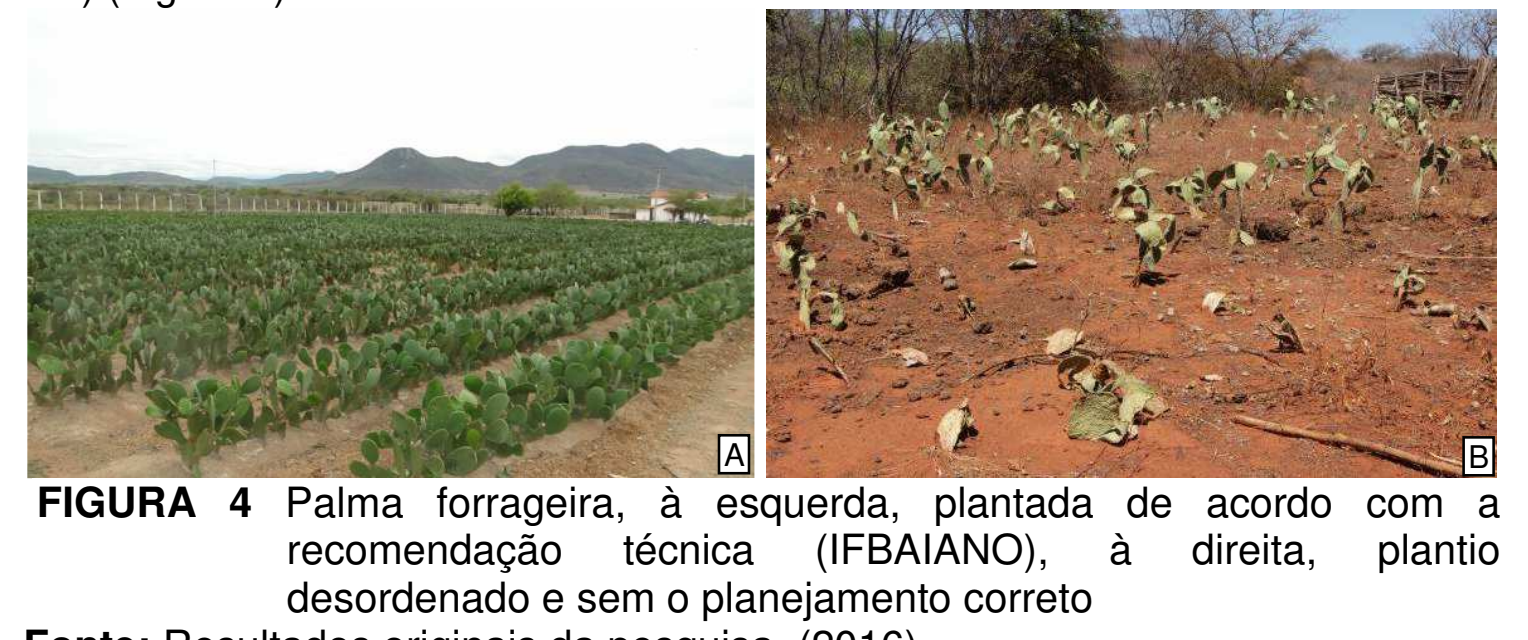

Fonte: Resultados originais da pesquisa, (2016)

\section{CONCLUSÕES}

O uso da tecnologia, recursos agronômicos, insumos zootécnicos e assistência técnica são ainda incipientes e restritos a poucos produtores rurais. Fato que reflete negativamente na baixa produtividade do leite e limita a geração de emprego e renda para a população com mão-de-obra contratada e fixa. Apesar disso, o manejo sanitário dos rebanhos leiteiros da região pesquisada atende as determinações do Ministério da Agricultura, Pecuária e Abastecimento [MAPA] (BRASIL, 2009), sobretudo no controle da febre aftosa.

Por ser a pecuária leiteira uma atividade predominante na região semiárida e muito importante para a economia local, a maioria dos produtores tem acesso e fazem uso das linhas de crédito para financiamento, com investimento em benfeitorias rurais, melhoramento genético dos animais, aquisição de máquinas e equipamentos. Entretanto, alguns produtores estão insatisfeitos com o preço pago pelo litro do leite.

Por fim, cabe ressaltar que as ações públicas e institucionais no sentido de implementar serviços de assistência técnica gratuita aos produtores rurais, promoção de cursos técnicos voltados para produção sustentável e racional de alimentos visando a estação da estiagem, aperfeiçoamento das práticas de manejo sanitário e nutricional, além das políticas de valorização do principal produto rural leite contribuem para melhorar a produção dos rebanhos e favorecer a permanência digna do homem no campo.

\section{AGRADECIMENTOS}

Os autores agradecem ao Banco do Brasil S/A, aos Institutos Federais: IFAM e IF-Baiano, à Universidade Estadual de Montes Claros - UNIMONTES e à Coordenação de Aperfeiçoamento de Pessoal de Nível Superior - CAPES pela bolsa e apoio financeiro ao desenvolvimento desse projeto. 


\section{REFERÊNCIAS}

AGUIAR, M. S. M. A.; SILVA, F. F.; DONATO, S. L. R.; RODRIGUES, E. S. O.; COSTA, L. T.; MATEUS, R. G.; SOUZA, D. R.; SILVA, V. L. Palma forrageira em dietas de novilhas leiteiras confinadas: desempenho e viabilidade econômica. Semina: Ciências Agrárias, Londrina, v. 36, n. 2, p. 1013-1030. 2015b. Disponível em: http://www.uel.br/revistas/uel/index.php/semagrarias/article/view/15766. Acesso em: 10 jul. 2016.

AGUIAR, M. S. M. A.; SILVA, F. F.; DONATO, S. L. R.; SCHIO, A. R.; SOUZA, D. D.; MENESES, M. A.; LÉDO, A. A. Síntese de proteína microbiana e concentração de ureia em novilhas leiteiras alimentadas com palma forrageira Opuntia. Semina: Ciências Agrárias, Londrina, v. 36, n. 2, p. 999-1012. 2015a. Disponível em: http://www.uel.br/revistas/uel/index.php/semagrarias/article/viewFile/15766/16208.

Acesso em: 10 jul. 2016.

ALMEIDA, B.; SILVA, E.; SILVA, F.; COSTA, A. M. Impacto da produtividade leiteira e qualidade morfológica das vacas leiteiras na rentabilidade económica das explorações. Revista de Ciências Agrárias, 2016, 39(2): 291-299.

\section{BARBETTA, P. A. O propósito do controle estatístico do processo em tempo real.

http://www.datalyzer.com.br/site/suporte/administrador/info/arquivos/info60/60.html. 2002. Acesso em: 10 jul. 2016.

BARROS, J. L.; DONATO, S. L. R.; GOMES, V. M.; DONATO, P. E. R.; SILVA, J. A.; PADILHA JÚNIOR, M. C. P. Palma forrageira 'gigante' cultivada com adubação orgânica. Revista Agrotecnologia, Ipameri, v.7, n.1, p.53-65. 2016. Disponível em http://www.revista.ueg.br/index.php/agrotecnologia/index. Acesso em: 12 jul. 2016.

BRASIL - Empresa Brasileira de Pesquisa Agropecuária [EMBRAPA] Gado de leite. 2014. Tecnologias para produção de leite na Região Semiárida do Brasil. Disponível em: http://www.cnpgl.embrapa.br/sistemaproducao/31introdu\%C3\%A7\%C3\%A3o-e-import\%C3\%A2ncia-econ\%C3\%B4mica. Acesso em: 22 jul. 2016.

BRASIL - Instituto Nacional de Colonização e Reforma Agrária [INCRA] - Disponível em: http://www.incra.gov.br/tamanho-propriedades-rurais. Acesso em 06 out. 2016.

BRASIL - Ministério da Agricultura Pecuária e Abastecimento [MAPA]. Plano de ação para febre aftosa/Ministério da Agricultura, Pecuária e Abastecimento. Secretaria de Defesa Agropecuária. - Brasília: MAPA/SDA/DSA, 96 p.: il. color.; 17 $\mathrm{cm}$. $2009 . \quad$ Disponível em: http://www.agricultura.gov.br/arq_editor/file/Aniamal/programa\%20nacional\%20sanid ade\%20aftosa/MIOLO_plano_acao.pdf. Acesso em 21 set. 2016.

CAIXÊTA, W. R. Socioeconomia e a atividade leiteira no município de Orizona/GO: um estudo dos produtores filiados ao sindicato rural. Enciclopédia biosfera, v.9, n.16; p.2657. Centro Científico Conhecer - Goiânia-GO, Brasil. 2013. Disponível em: 
http://www.conhecer.org.br/enciclop/2013a/miltidisciplinar/SOCIOECONOMIA.pdf. Acesso em: 12 nov. 2016.

CAMPOS, K. C. Agronegócio do leite: cenário atual e perspectivas. 2007. Disponível em: http://www.sober.org.br/palestra/6/1152.pdf. Acesso em: 28 out. 2016.

EURICH, J.; WEIRICH NETO, P. H.; ROCHA, C. H. Pecuária leiteira em uma colônia de agricultores familiares no município de Palmeira, Paraná. Revista Ceres, Viçosa, v.63, n.4, p.454-460, jul/ago, 2016. DOI: 10.1590/0034-737X201663040004. Disponível em: http://www.scielo.br/pdf/rceres/v63n4/2177-3491-rceres-63-0400454.pdf. Acesso em: 15 fev. 2017.

FERRAZZA, R. A.; LOPES, M. A.; MORAES, F.; BRUHN, F. R. P. Índices de desempenho zootécnico e econômico de sistemas de produção de leite com diferentes níveis tecnológicos. Semina: Ciências Agrárias, Londrina, v.36, n.1, p. 485-496, jan./fev. 2015. DOI: 10.5433/1679-0359.2015v36n1p485. Disponível em: file://C:/Users/bvini/Desktop/445744146038.pdf. Acesso em: 15 fev. 2017.

LEMES, K. C. Produção rural familiar no Brasil: as comunidades de Firmeza e Taquaral - Orizona (GO) (2009). Disponível em: http://egal2009.easyplanners.info/area06/ 6068 Costa_Lemes_Katia.doc. Acesso em: 26 set. 2016.

MILKPOINT. Gestão da Propriedade leiteira - o que os números têm a dizer? Espaço aberto. 2014. Disponível em: http://www.milkpoint.com.br. Acesso em 21 set. 2016.

MOTA, D. M.; SÁ, C. O.; SÁ, J. L. Dinâmica recente no espaço rural do município de Nossa Senhora da Glória/SE. Revista Brasileira de Agroecologia, v, 5, n. 2, p. 126-138. 2010. Disponível em: https://www.alice.cnptia.embrapa.br/alice/handle/doc/957424. Acesso em 21 set. 2016.

NASCIMENTO, I. R.; SANTOS, A. M. B.; MENDONÇA, V. M.; Santos, I.F. Diversificação das atividades produtivas e as perspectivas de adoção de técnicas agroecológicas em sistema leiteiro no semiárido sergipano. Cadernos de Agroecologia - ISSN 2236-7934 - v.9, n.4, nov/2014. Disponível em: file://C:/Users/bvini/Downloads/16545-68124-1-PB.pdf. Acesso em 22 nov. 2016.

NEVES, A. L. A.; PEREIRA, L. G. R.; SANTOS, R. D.; ARAÚJO, G. G. L.; CARNEIRO, A. V.; MORAES, S. A.; SPANIOL, C. M. O.; ARAGÃO, A. S. L. Caracterização dos produtores e dos sistemas de produção de leite no perímetro irrigado de Petrolina/PE. Revista Brasileira de Saúde e Produção Animal, Salvador, v.12, n.1, p.209-223 jan/mar, ISSN 1519 9940. 2011. Disponível em: http://www.rbspa.ufba.br. Acesso em 22 nov. 2016. 
NEY, M. G.; HOFFMANN, R. Educação, concentração fundiária e desigualdade de rendimentos no meio rural brasileiro. Revista de Economia e Sociologia Rural, v.47, n.1, p.147-181. 2009. Disponível em: http://www.scielo.br/scielo.php?script=sci_nlinks\&ref=000045\&pid=S1519$9940201200020000100010 \&$ Ing=en. Acesso em 22 nov. 2016.

PACHAURI, R. K.; MEYER, L. Impactos, Adaptação e Vulnerabilidade. Sumário para tomadores de decisão. WGIl AR5. São Paulo: Iniciativa Verde. 2015. Disponível em: https://www.embrapa.br/documents/1355117/1528925/Panorama+do+Leite++outubro+2015/f97da482-483f-4451-bd26-e9f7e1d95c4b. Acesso em: 22 jun. 2016.

PADILHA JUNIOR, M. C.; DONATO, S. L. R.; SILVA, J. A. S.; DONATO, P. E. R.; SOUZA, E. S. S. Características morfométricas e rendimento da palma forrageira 'Gigante' sob diferentes adubações e configurações de plantio. Revista Verde de Agroecologia e Desenvolvimento Sustentável, v.11, n.1, p. 67-72. 2016. Disponível em: http://www.gvaa.com.br/revista/index.php/RVADS. Acesso em: 22 jun. 2016.

SÁ, C. O.; MARINHO, G. L. O. C.; SÁ, J. L.; RONER, M. N. B.; NASCIMENTO, I. R.: SÁ, F. P. Sustentabilidade dos sistemas de produção dos agricultores familiares e produtores de queijo em Nossa Senhora da Glória, semiárido sergipano. Revista Brasileira de Agroecologia, v.7, n.3, p. 26-39, 2012. Disponível em: http://www.aba-

agroecologia.org.br/revistas/index.php/rbagroecologia/article/view/12684. Acesso em: 22 jun. 2016.

SALGADO, F. M. M. O FUTURO DO LEITE NO BRASIL: Uma análise de ambiente da cadeia produtiva de lácteos. Dissertação (Mestrado em Ciência e Tecnologia do Leite e Derivados) —Universidade Federal de Juiz de Fora, Juiz de Fora, 2013.

SILVA, G. S. L.; SILVA, J. B. A importância da definição de um modelo de negócio na pecuária leiteira para a escolha da estratégia de comercialização. Revista de Administração do Sul do Pará (REASP) - FESAR - v.3, n.2, mai/ago - 2016.

SILVA, J. A.; DONATO, S. L. R.; DONATO, P. E. R.; SOUZA, E. S. S.; PADILHA JÚNIOR, M. C.; SILVA JUNIOR, A. A. Extraction/export of nutrients in Opuntia ficusindica under different spacings and chemical fertilizers. Revista Brasileira de Engenharia Agrícola e Ambiental. Campina Grande, PB, UAEA/UFCG. v.20, n.3, p.236-242. 2016. Disponível em: http://www.agriambi.com.br. Acesso em: 22 jun. 2016.

SOARES, F. U. Análise da Cadeia Produtiva Leiteira. Seminários Aplicados do Programa de Pós-Graduação em Ciência Animal, nível Doutorado, da Escola de Veterinária e Zootecnia da Universidade Federal de Goiás. UNIVERSIDADE FEDERAL DE GOIÁS ESCOLA DE VETERINÁRIA PROGRAMA DE PÓSGRADUAÇÃO EM CIÊNCIA ANIMAL. GOIÂNIA, 2012. 
WIRBISKI, S.; BAZOTTI, A.; NAZARENO, L. R.; SUGAMOSTO, M.; WAVRUK, P. Caracterização Socioeconômica da Atividade Leiteira do Paraná. 2009. Sober $47^{\text {a }}$ congresso da sociedade Brasileira de economia, administração e sociológica rural, Porto Alegre 26 a 30 de julho de 2009.Disponível em: http://www.sober.org.br/palestra/13/602.pdf. Acesso em 28 maio. 2016.

ZOCCAL, R. SOUZA, A. D. LEITE, J.B. Produção de Leite na Agricultura Familiar (2003). Disponível em: http://www.sober.org.br/palestra/12/090433.pdf. Acesso em: $28 \mathrm{mai} / 2016$. 